\title{
A TRANSFORMAÇÃO D'OS SERTÕES NAS TRADUÇÕES PARA O INGLÊS
}

ZeLina BEATO*

Aryadne Bezerra de ARAÚJO**

\section{RESUMO}

O pensador da desconstrução, Jacques Derrida, dedica parte da sua obra à reflexão em torno da tradução. O filósofo rompe com o ideal de tradução como representação ao assumir essa atividade como maturação e sobrevida de um texto original que não acontecem sem transformação daquilo que se traduz. Partindo dessa perspectiva, refletimos em torno da tradução da obra mestra de Euclides da Cunha, Os sertões: Campanha de Canudos. Para esta discussão, elegemos as duas traduções para o inglês, a primeira, escrita em 1944, por Samuel Putnam, e a mais recente, de 2010, por Elizabeth Lowe.

PalaVRas-ChaVe: Tradução, transformação, Os sertões.

\section{PRELIMINARES: O CONFLITO TRADUTÓRIO}

A propósito do pensamento de Walter Benjamin (1996) acerca da tradução, em que essa tarefa não se resume à produção de imagem de um original, especialmente em Torres de Babel, que escreveu justamente a propósito d'A tarefa do tradutor de Benjamin (2001, 2002), Derrida torna explícito o rompimento com o ideal estruturalista que ronda o processo tradutório. Ressaltamos, entretanto, que a herança sobre a qual falamos segue a própria noção derridiana do termo, cujo valor não se restringe à mera repetição do que se herda. Mas fala, sobretudo, de uma herança sob rasura, aberta à assinatura daquele que herda. Assinatura

* Professora adjunta do Departamento de Letras e Artes da Universidade Estadual de Santa Cruz (UESC), Ilhéus, Bahia, Brasil. Membro permanente do Programa de Pós-Graduação em Letras Linguagens e Representações (UESC). E-mail: zell.beato@gmail.com.

** Mestra em Letras Linguagens e Representações pela Universidade Estadual de Santa Cruz (UESC), Ilhéus, Bahia, Brasil. Mestrado concluído com concessão de bolsa pela Coordenação de Aperfeiçoamento de Pessoal de Nível Superior (Capes). E-mail: aryadne.araujo@gmail.com. 
que se mostra como traço de hereditariedade e, ao mesmo tempo, de subversão à ideia de conservar intocado certo legado. Assim, nos diz Derrida (2005, p. 193): “é preciso, na finitude, interpretá-la [a herança] 'filtrá-la', deixando-se transbordar por ela”. Seguindo essa lógica, é pertinente afirmar que o filósofo franco-magrebino é herdeiro não apenas do pensamento de Benjamin, mas também da linguística de Saussure, da escrita de Nietzsche, do arquivo de Freud etc. Todas essas heranças, entretanto, não escaparam a uma leitura desconstrutora que guarda sempre certa violência. A exemplo disso, discutiremos a desconstrução da concepção de signo linguístico que a tradução, em si, encena.

A reflexão benjaminiana em torno da tarefa tradutória ressoa na leitura crítica engendrada por Derrida acerca da determinação linguística sobre a tradução. De fato, há rastros da escrita de Walter Benjamin não apenas no que Derrida legou, mas também no entorno da crítica contemporânea à concepção estruturalista de tradução como reescrita de um mesmo significado. Tendo em vista que o filósofo compromete a Desconstrução à questão da tradução, atentaremos para a leitura derridiana acerca dessa atividade.

A ótica estruturalista, com o qual Benjamin e Derrida rompem, confia ao tradutor o dever de reescrever e conservar o sentido original, fantasma que ainda paira como um espectral sobre a atividade tradutória. O próprio tradutor anseia cumprir a tarefa premente de conservar um sentido, um estilo ou uma intenção original, temendo uma possível acusação de perjúrio. Entretanto, sua prática testemunha a inviabilidade desse ideal de tradução.

Seguindo a lógica estruturalista, as línguas são sistemas passíveis de análise, descrição e normatização em estruturas que supostamente se repetem sob a forma de palavras distintas. Sob essa ótica, todas as línguas são determinadas por um sistema maior, em que partilham um mesmo núcleo de significados e os transmitem através de palavras ou significantes equivalentes. No âmbito tradutório, essa concepção de língua é reforçada, por exemplo, pelo linguista John Cunnison Catford, para quem a tradução resumir-se-ia à troca de um significante por outro que o representasse como mesmo na língua-alvo. Isto é, a tradução seria "a substituição de material textual de uma língua por material textual equivalente em outra" (CATFORD, 1980, p. 22). 
A noção de tradução como troca equivalente de significantes ou palavras é colocada em xeque na prática tradutória mesma. Ilustra a impossibilidade dessa equivalência a investigação que aqui propomos das duas traduções d'Os sertões para o inglês. Nessa análise, podemos argumentar que a tarefa do tradutor não se restringe a dizer o mesmo com outras palavras, a reproduzir uma "voz" original na sua língua. Em contrapartida, é esse mesmo significado e essa voz autoral que o tradutor deseja e busca repetir, como observamos no depoimento da tradutora Elizabeth Lowe, incumbida da retradução d'Os sertões.

$\mathrm{Na}$ tentativa de repetir um original, de dizer o mesmo, dizse alguma coisa a mais. É nesse sentido que Derrida $(2001,2002)$ e Benjamin (1996) advogam a favor da tradução como tarefa que inevitavelmente produz a transformação do original, e não sua cópia. Conforme Derrida,

nos limites em que ela é possível, [...], a tradução pratica a diferença entre o significado e o significante. Mas se essa diferença não é nunca pura, tampouco o é a tradução, e seria necessário substituir a noção de tradução pela de transformação: uma transformação regulada de uma língua por outra, de um texto por outro (DERRIDA, 2001, p. 26).

Não obstante a impossibilidade de repetir e, desse modo, transportar integralmente à língua de chegada um original e seus sentidos, o tradutor é movido pela necessidade de realizar esse transporte. Tal é o conflito tradutório anunciado por Walter Benjamin (1996), em A tarefa do tradutor: ser movido pela necessidade de "dizer o mesmo" e impossibilitado de cumprir tal tarefa. Na tarefa de traduzir, é exigida do tradutor a promessa de trazer a uma língua de chegada um sentido supostamente guardado no texto original. Tarefa que o tradutor atesta ser impossível, pois, como observa Rosemary Arrojo (1999, p. 38), "nenhum texto é receptáculo de conteúdos estáveis e mantidos sob controle, que podem ser repetidos na íntegra". Em outras palavras, o sentido não está enclausurado no texto, tampouco limitado às intenções do seu autor. Além desse caráter da escrita contraditório à concepção de sentidos imutáveis, a autora adverte que não está ao alcance de nenhum tradutor impedir que seu "contato com os textos (e com a própria 
realidade) seja mediado por suas circunstâncias, suas concepções, seu contexto histórico e social" (ARROJO, 1999, p. 38).

O processo tradutório, então, transfigura-se no palco de uma luta com a língua para traduzir o que resiste à tradução. $\mathrm{O}$ tradutor é testemunha privilegiada dessa luta ou, em termos derridianos, desse corpo-a-corpo das línguas (DERRIDA, 2007). Em sua tarefa, o tradutor vivencia e é afetado pela incapacidade das palavras de transportar sentidos completos. É assombrado pelo imperativo de (re)escrever um original que resiste à tradução, que se rebela contra a tentativa de repetição integral. O tradutor testemunha a angústia de ser desamparado pela "própria" língua ao tentar findar seu compromisso de repetir uma "verdade" original. Atesta que a língua, já mesmo no original, não diz tudo. Tal é o terreno marcado pelo double bind que incide sobra a tarefa tradutória, ou seja, a dupla injunção dessa tarefa, a impossibilidade e a necessidade imperiosa de cumpri-la.

Nesse sentido, aqui vamos argumentar que a escrita euclidiana é duplamente performática no que concerne à impossibilidade e ao desejo imperativo de traduzi-la. Os dois tradutores d'Os sertões testemunham a relação angustiante entre a necessidade e a impossibilidade de traduzir uma narrativa ademais tão idiomática como é o relato de Euclides da Cunha e tão exemplar de um tema universal como a história do massacre de um povo que ameaça "a identidade" nacional.

\section{DUAS TRADUÇÕES DE UM “MESMO” ORIGINAL E UMA PROMESSA INFINDÁVEL}

Em 1944, é lançada a primeira tradução para o inglês do livro que narra a guerra de Canudos. Essa primeira tradução de Samuel Putnam traz uma introdução e um glossário das mãos do próprio tradutor e que Elizabeth Lowe (2014), como ela mesma afirma, provou ser imensamente útil no seu projeto (re)tradutório publicado em 2010. As duas traduções guardam sinais de duas diferentes leituras de um "mesmo" original, gerando, inevitavelmente, transformações. A segunda tradução, como de resto qualquer processo de retradução, propõe retornar ao original na busca por sentidos que, em alguma instância, não foram suficientemente registrados na primeira tradução. 
Lowe promete retornar ao original e "resgatar" alguma coisa que a primeira tradução falhou em reproduzir. Mas, ao contrário do que se promete, atestamos na segunda tradução a disseminação inevitável de sentidos e a consequente transformação do texto chamado original. $\mathrm{Na}$ medida em que se tenta apreender e dominar o original, ele se desloca e se revela inapreensível. A nova tradução é mais um testemunho de que a língua não transporta sentidos puros e inteiros, nem dentro de uma mesma língua e, menos ainda, numa língua outra.

Os depoimentos dos tradutores lançam luz sobre a árdua tarefa de traduzir a narrativa testemunhal de Euclides, enquanto por si mesmos testemunham a diferença entre a língua do original e a língua de chegada. Enfrentam as palavras que resistem impenetráveis para traduzir Os sertões.

$\mathrm{Na}$ sua introdução, Putnam inscreve sua impressão sobre a singularidade da linguagem d'Os sertões. Diferencia-a, inclusive, da linguagem empregada por Euclides em outras produções escritas como, por exemplo, no que escreve sobre a Amazônia, texto que o tradutor julga ter certa exuberância tropical. Ele, então, descreve a escrita de Euclides da seguinte forma:

Em outros momentos - na maior parte do tempo - sua prosa não é tropical, mas áspera, áspera como o próprio sertão; é nervosa, dramaticamente intensa, escultural como os montes do interior e caracteriza-se por uma resistência definitiva e brusca ao lirismo e uma ênfase no ponto que se revela angustiante e doloroso (PUTNAM, 1944, p. ix, tradução nossa) ${ }^{1}$.

A intensidade dramática e a ênfase na angústia e na dor são percepções que evidenciam como a linguagem d'Os sertões afetou também o tradutor. No seu contato com a escrita euclidiana, Putnam testemunhou a angustia de que fala. O processo tradutório não se deu de forma branda e isenta de perturbações, mas atravessado por uma tensão inevitável entre tradutor e texto original.

Retomando o tema da singularidade da obra, Putnam (1944) pontua a originalidade de Euclides em elaborar uma nova forma, um vocabulário e um estilo tão originais que não poderiam ser assimilados em qualquer molde até então conhecido. Os sertões surgem como um 
acontecimento nunca antes vivido e experimentado. Falar desse aspecto da obra, texto que já na sua língua é concebido como escrita original, diferente ou única, fornece índices da dificuldade vivenciada pelo tradutor na tentativa de traduzir essa "originalidade".

A despeito do argumento comum entre alguns críticos da intraduzibilidade d'Os sertões e de que sua leitura só deveria acontecer na língua original, as traduções acontecem e Putnam menciona a primeira tradução feita por Benjamín de Garay. Segundo Putnam, a tradução argentina é "uma valiosa contribuição para a causa do entendimento cultural nesse hemisfério e espera-se que uma tradução na língua inglesa possa servir ao mesmo fim" (PUTNAM, 1944, p. viii, tradução nossa) ${ }^{2}$. O tradutor parece reconhecer a dificuldade e os limites da tradução de um original como Os sertões, mas reconhece também a importância e a necessidade de propagar na língua de chegada o conhecimento cultural difundido por Euclides. Em alguma instância, Putnam reconhece a impossibilidade e a necessidade da tarefa tradutória, declarando-se já submetido ao double bind da tradução. Sua tarefa tradutória se desenrola, portanto, entre os limites de traduzir e, assim, "universalizar" um texto marcado por sua singularidade, e as dificuldades de fazê-lo.

Cumprida, de certa forma, a tarefa de difundir uma cultura e tornar a obra mestra de Euclides familiar a leitores da língua-alvo, o que de novo deve trazer a retradução da narrativa de um mesmo original para uma mesma língua? Há diversos fatores que justificariam a necessidade de uma nova tradução, entre eles, a possível promessa de uma leitura "mais fiel" do original. A respeito disso, a autora da recente tradução para o inglês d'Os sertões, Elizabeth Lowe, fornece-nos pistas importantes.

Em um texto em que justifica a necessidade da retradução, Lowe (2014) esclarece as razões que sustentam a tradução de obras numa língua para a qual já foram traduzidas. Na sua reflexão, não poderia faltar o relato da sua experiência ao retraduzir Os sertões.

A primeira justificativa envolve a proposta da editora Penguin Classics de promover um retorno ao original por meio de uma tradução mais "fiel" e, ao mesmo tempo, acessível ao leitor-alvo. A expectativa da tradutora é de que a nova tradução recuperasse aspectos do texto 
de partida ou da "voz" autoral que a versão anterior "falhou" em reproduzir. Da mesma forma, seria de se esperar que a segunda tradução proporcionasse uma leitura mais acessível ao público contemporâneo, como foi a proposta da editora.

Podemos argumentar que tal justificativa aponta para a noção de tradução guiada pelo ideal de fidelidade como repetição. Por outro lado, ser fiel, nos termos desse comprometimento tradutório, não deve significar uma despreocupação com o leitor. Ele deve pesar em um dos lados da balança, concorrendo com o autor. $O$ tradutor aqui deve comprometer-se duplamente, na fidelidade ao original e ao texto de chegada. $\mathrm{O}$ tradutor deve prometer a autor e leitor a repetição do mesmo. Firma-se, então, um duplo compromisso ou uma promessa de fidelidade a mais de $\mathrm{um}^{3}$ : àquele que chegou/escreveu antes, o autor, e àquele que está por vir, o leitor.

Cabe indagar se essa dupla promessa de fidelidade é, no final das contas, uma missão possível ao traduzir Os sertões, escrita de um evento "ilegível", nas palavras do próprio autor. Como Euclides expressa em carta a José Veríssimo, o livro constitui uma tentativa de "dizer a verdade sobre uma fase, ainda ilegível, da nossa história” (CUNHA, 1901 apud GALVÃO, 2009, p. 200). Ou seja, Os sertões carregam, já em sua origem, aquilo que permaneceu ilegível para o autor, mesmo após seus esforços em traduzir e tornar legíveis os eventos que marcaram uma fase ainda sombria da nossa história. Euclides ambicionava dizer a "verdade" por trás da tragédia de Canudos e dar um diagnóstico a esse evento obscuro. Seu diagnóstico foi de que a campanha constituiu um crime. No fim, o que restou foi a certeza de que ela é uma mancha, uma ferida na história da jovem república, para a qual não há palavras capazes de traduzir de forma satisfatória. $\mathrm{O}$ original figura a tentativa incansável de simbolizar a guerra no sertão. Ora, se o autor conclui que a fase permanece sombria e ilegível, confessa ele mesmo ter sido testemunha de um fato inenarrável. Euclides é testemunha de que não há, de fato, o lugar, a língua e as palavras exatas para traduzir o horror que presenciou. Se nem Euclides pôde sanar as dificuldades em traduzir essa ferida, tampouco espera-se de seus tradutores que o façam. Os sertões carregam, como qualquer texto, essa marca de ilegibilidade, esse rastro intocável próprio da língua. 
Há um grande repertório engendrado para traduzir e explicar o que, no fim, se manteve intraduzível/ilegível. A riqueza vocabular d' $O s$ sertões resulta num intricado jogo interpretativo que assombra e, ao mesmo tempo, fascina pela forma poética em que estão organizados os termos carregados de erudição e, como tais, estranhos ao discurso comum.

Somados à opulência de vocábulos científicos, eruditos ou regionais na frase poética, há outros traços estilísticos da escrita euclidiana que contribuem para que esta seja lugar próprio de uma leitura perturbadora e angustiante. Um deles é a existência de inúmeras linhas descrevendo ações de um sujeito que, quando não suprimido, surge no final do parágrafo. Ilustra essa marca o seguinte parágrafo que encerra o capítulo testemunhal "Depoimento do autor":

mas que entre os deslumbramentos do futuro caia, implacável e revolta; sem altitude, porque a deprime o assunto; brutalmente violenta, porque é um grito de protesto; sombria, porque reflete uma nódoa - esta página sem brilhos... (CUNHA, 1952, p. 507).

No final do pensamento, separado por um travessão, está o elemento principal do qual se fala e sobre o qual desaba a sequência de adjetivos intercalados de pequenas justificativas. Com essa estrutura frásica invertida (verbo e sujeito), e a quebra antes do fim - fim adiado pelos três pontos - , chama a nossa atenção esse final, no qual está aquilo que figuraria no início, numa lógica sintática comum. Em meio a uma sequência de informações sobre um sujeito ainda não revelado, miramos aquele elemento final, como quem vê um feixe de luz se destacando lá longe, ali onde lemos: "esta página sem brilhos".

Esse é um dos inúmeros casos em que atestamos certa complexidade e o teor poético dessa escrita afetada pelo trauma que Euclides testemunha. $\mathrm{O}$ fragmento exposto é índice de uma parcialidade que se deve reprimir no relato meramente histórico. É, portanto, traço estilístico da escrita literária de Euclides e, como tal, tão singular como sua assinatura e sua voz.

Essa singularidade do estilo e da "voz" euclidianos que Lowe promete resgatar na sua tradução, ao mesmo tempo em que se compromete a tornar a narrativa mais acessível, ou seja, menos estranha 
ao público-alvo. A tradução do parágrafo acima representa o quão desafiador foi cumprir sua dupla promessa:

Let this simple passage be read in the bright light of the future. It is not brilliant. It is not written in elevated language, because the subject is depressing. It is a blunt and angry cry of protest against the dark stain of bloodshed that we have seen being commited on this battlefield (CUNHA, 2010, p. 435).

Segundo Lowe (2014), um dos aspectos que a tradução de Putnam falhou em resgatar, e que também é apontado pelos críticos Paula Straile e Earle Fitz, é a despreocupação em transportar o estilo e a forma originais. Se considerarmos a forma desse trecho, um exemplo de construção frásica recorrente na narrativa, percebemos que, na tradução de Lowe, a forma permanece irreproduzível. Transportar a forma ou o estilo não é uma tarefa que dependa exclusivamente do tradutor. Como observamos no caso em análise, a língua de chegada é determinante na possibilidade de se reproduzir a forma, em que verbo e adjetivos antecedem o sujeito. Na tarefa de traduzir, a forma, a língua e seus mecanismos são justamente a primeira vítima, os primeiros que se perdem na travessia de uma língua a outra. Percebemos, também nesse trecho, que a tradutora necessitou acrescentar a seguinte informação: "of a bloodshed that we have seen being commited on this battlefield" ("de um massacre que vimos ser cometido nesse campo de batalha"). No trecho original, fala-se de uma nódoa sem descrevê-la. A tradutora, portanto, viu-se compelida a modificar/transformar esse trecho do original.

Considerando as dificuldades que a escrita original de Euclides deve impor ao leitor e, por conseguinte, ao tradutor, é pertinente questionar a possibilidade de ser fiel ao rastro original inassimilável quando se espera do tradutor a entrega de um texto legível na língua de chegada. Inassimilável na medida em que o texto escapa incessantemente ao desejo quimérico do tradutor de possuí-lo, como atesta o tradutor francês Seel (2002).

Essas pausas sublimes onde o tempo faz sentir tanto seu peso quanto sua beleza, sua paz e sua grandeza, correspondem a uma abertura do texto - uma abertura que, dessa vez, não é um rasgo ou uma 
falha, mas um desdobramento infinito, uma abertura na qual o texto se perde, confrontado àquilo que não tem limites (SEEL, 2002, p. 154).

Atesta também Seel a impossibilidade da dupla fidelidade com a qual Lowe se endividou ao estar diante de um texto que se abre a um desdobramento infinito.

Antes da impossibilidade de ser duplamente fiel, já é problemático falar de uma fidelidade ao original. O que está em jogo no compromisso de Lowe, como afirma, é mais a preocupação com a forma do que o cuidado em transmitir um "mesmo" sentido. Preocupação que também era a de Walter Benjamin (1996), para quem a lei que deve reger a tradução reside mais na forma que em um sentido original. Entretanto, como constatou o filósofo, a semelhança à forma original jamais é alcançada na tradução. Ele argumenta que

[...] pode-se comprovar não ser possível existir uma tradução, caso ela, em sua essência última, ambicionasse alcançar alguma semelhança com o original. Pois em sua continuidade vital (que não mereceria tal nome se não constituísse em transformação e renovação de tudo aquilo que vive) o original se modifica (BENJAMIN, 1996, p. 293, grifo nosso).

A tradução constitui, desse modo, uma transformação do texto de partida, representa um ponto de renovação, de crescimento ou de maturação do original. Não é, entretanto, uma transformação qualquer, como vimos em Derrida (2001), deve ser uma transformação regulada pelos limites impostos pelas línguas e pelos textos. A lei que regula e governa essa transformação está na forma original. Se o tradutor busca a fidelidade à forma, no sentido corrente em que se usa a palavra fidelidade, isto é, no sentido de reprodução, sua promessa já se mostra infindável.

É justamente a reprodução da forma o que constituiu grande inquietação na tarefa tradutória de Lowe. Como é possível falar de uma fidelidade à forma quando a primeira coisa que não resiste à tradução é, precisamente, essa materialidade linguística? A forma, que é o corpo textual, isto é, o conjunto de significantes através do qual o texto fala, é aquilo mesmo que passa por uma transformação radical. Ainda assim, 
a tradutora promete transportar esse corpo linguístico apenas possível na língua original. Considera um "problema" na tradução existente a aparente despreocupação com a forma. É imposta à nova tradução, portanto, a tarefa impossível de entregar uma reescrita mais "fiel" nesse sentido.

Antes mesmo de se pensar na possibilidade de uma reescrita mais fiel à forma do original, é importante saber onde, exatamente, a primeira tradução "traiu". Tal premissa parece ter guiado Lowe quando decidiu partir da busca por uma voz n'Os sertões que a versão de Putnam não conseguiu revelar na íntegra. Nesse sentido, a tradutora pretende testemunhar (para) uma voz original que talvez não tenha sobrevivido na tradução de Putnam.

No decorrer da sua reflexão, Lowe pontua algumas descobertas feitas durante essa fase analítica da sua tarefa. Entre elas, uma atenção especial ao aspecto ambivalente da obra, oscilante entre passagens poéticas de grande valor emotivo e uma escrita pretensamente imparcial de um correspondente de guerra. Esse estilo intergenérico, que a tradutora promete recriar, ela não viu reproduzido na versão de Putnam que, como insiste, enfatiza mais o conteúdo em detrimento do estilo euclidiano.

A percepção de Putnam acerca do original justifica essa ênfase no conteúdo. Comparando Euclides a Machado de Assis, Putnam assinala que o autor d'Os sertões, diferente do seu contemporâneo, atém-se mais ao conteúdo que à forma. Mas isso não quer dizer que há, nessa afirmação do tradutor, uma despreocupação total com a forma. $\mathrm{Na}$ concepção de Putnam, Euclides traz brilhantemente à tona o problema de "como alcançar uma síntese artística do rico conteúdo social que seu país oferece-lhe" (PUTNAM, 1944, p. vii, viii, tradução nossa)4.

Se, para o primeiro tradutor, o mais essencial n'Os sertões são os assuntos, as questões sociais e o relato da guerra de Canudos que Euclides foi pioneiro em tratar com tanta profundidade, para Lowe, os aspectos relevantes seriam a linguagem e o estilo de Euclides que culminam no traço intergenérico da narrativa, oscilante entre a literatura e a ciência.

Lowe, portanto, afirma ter encontrado uma escrita euclidiana que não aparece na versão de Putnam. Entretanto, esse estilo ao qual a 
tradutora refere-se como "a voz autoral", percebido e visto no original, é o que surge na sua experiência como leitora e tradutora. Não é possível traduzir aquilo que não se percebe, como não é possível testemunhar o que não se presenciou.

Além disso, muitos traços que Lowe pontua como característicos da escrita de Euclides e marcas do seu estilo não podem ser repetidos na sua língua. A maior parte deles é de ordem sintática, o que torna ainda mais difícil uma reprodução, visto que as leis sintáticas do português divergem significativamente daquelas que regem a frase na língua inglesa. A título de exemplo, a tradutora aponta como parte constituinte de um estilo euclidiano a recorrência de elipses, das supressões de elementos componentes da frase. As elipses, raras em textos científicos e recorrentes na linguagem estética, chamam atenção para si, intensificam, segundo a tradutora, o efeito dramático n'Os sertões. A extinção delas na tradução de Putnam é vista como parte de sua fraqueza. Todavia, como manter supressão de elementos que as leis da língua de chegada não permitem suprimir? A diferença entre as línguas constitui um obstáculo intransponível para a promessa de fidelidade. A materialidade do texto, os significantes e a forma como se organizam são o que não se pode repetir e resgatar na tradução. Como nos diz Derrida (2007), traduzir sempre implicará produzir uma violência no corpo poético.

Outro momento em que observamos essa violência no corpo, que é também a sua transformação pela tradução, aparece na última página da narrativa, no capítulo intitulado "Duas linhas":

É que ainda não existe um Maudsley para as loucuras e os crimes das nacionalidades... (CUNHA, 1952, p. 543).

The trouble is that we do not have a Maudsley for acts of madness and crimes on the part of nations... (CUNHA, 1944, p. 479).

It is truly regrettable that in these times we do not have a Maudsley, who knew the diference between good sense and in-sanity, to prevent nations from commiting acts of madness and crimes against humanity. (CUNHA, 2010, p. 465). 
Nesses trechos, as leituras de cada tradutor estão marcadas nas traduções, testemunhando a inevitável disseminação dos sentidos do original. $\mathrm{O}$ que se apresenta na forma de uma linha e meia no texto de partida e na tradução de Putnam transforma-se em mais de três linhas de palavras na versão de Lowe. Buscamos reproduzir aqui o trecho tal como nas versões consultadas. Na versão de Lowe, há uma extensão do texto e informações que não se vê no original, mas que são resultado de uma incorporação da nota de rodapé. Esta, que foi excluída na tradução recente, remete à página 134, em que Euclides, a despeito da personalidade de Antônio Conselheiro, menciona o psiquiatra inglês Maudsley: "a sua frágil consciência oscilava em torno dessa posição média, expressa pela linha ideal que Maudsley lamenta não se poder traçar entre o bom senso e a insânia" (CUNHA, 1952, p. 134). Na página indicada na nota de rodapé, Euclides reforça que o psiquiatra lamenta não ser possível traçar uma linha, isto é, marcar o limite entre bom senso e insânia. Lowe, por sua vez, escreve, em meio ao capítulo "Duas linhas" ("Two lines"), que Maudsley era "quem sabia a diferença entre bom senso e insânia" ("Who knew the diference between good sense and insanity”). Na tradução mais recente, houve mudança tanto na forma quanto no conteúdo. O que eram duas linhas passa a ocupar quatro; o psiquiatra que, segundo Euclides, não podia marcar o limite ideal entre bom senso e insânia é, para Lowe, quem sabia a diferença entre tais estados mentais. Ao contrário da fidelidade pretendida e impossível, a segunda tradução revelou-se ainda mais modificadora da forma e do sentido originais.

\section{ÚLTIMAS CONSIDERAÇÕES}

A tradutora que se comprometeu a "resgatar" uma voz no original e prestar-lhe fidelidade não fez senão transformar, fazer o que Euclides não fez. Sabemos, desde já, que transformações são inevitáveis no processo tradutório, uma verdade que se sobressai mesmo na tarefa do tradutor que refuta tal condição. Aqui, se marca a tensão presente no processo tradutório, que, conforme Derrida (2005), constitui a própria tradução: "uma tensão entre a estratégia de 
transformação da língua de chegada, de um lado, e a fidelidade quase sagrada, de outro" (DERRIDA, 2005, p. 196).

O desejo utópico de apropriar-se do original, de uma voz supostamente presente nele e reproduzi-la de forma idêntica encontra a resistência do original em se deixar possuir, deslocandose continuamente e proporcionando ao leitor/tradutor sempre novas descobertas. Nessa tensão entre necessidade e impossibilidade de repetição de um original que, nesse caso, é Os sertões, ele se transforma e se dissemina na tentativa vã de ser mais fiel. As duas traduções para uma mesma língua dão testemunho dessa transformação, e a última tradução, com a promessa de fidelidade e semelhança, é testemunho do que Benjamin (1996) atestou na sua experiência de tradutor e deixou como legado para aqueles que se debruçam sobre o traduzir: "em sua continuidade vital [...] o original se modifica" (BENJAMIN, 1996, p. 293).

Mas a impossibilidade de um texto manter-se o mesmo, apresentando-se imutável, não se restringe a uma condição de texto original a ser traduzido. É condição de qualquer texto, seja escrito, seja falado ou traduzido, o não pertencimento exclusivo de seus significados a um autor, a uma língua, a um contexto ou a uma cultura. Adisseminação própria da construção de sentidos pelo leitor fica marcada nas tentativas explicativas de Lowe como resposta à demanda de legibilidade para o leitor da tradução. A inevitável separação entre o instante que se deseja arquivar na língua e sua escrita é condição própria da língua, que não repete um acontecimento sem se render ao processo da disseminação, à deriva de infinitas leituras transformadoras. É nesse sentido que as palavras não traduzem tudo e, ao mesmo tempo, "extradizem, sobredizem, $[. .$.$] mas deixam de fora a dor, a grande dor silenciosa de$ nem tudo poder dizer" (BEATO, 2009, p. 179). A tradução na língua nunca acontecerá até o fim, alguma coisa permanecerá silenciosa e secreta. Tal é a limitação que testemunhamos na nossa relação nunca tranquila com a língua. 
THE TRANSFORMATION OF OS SERTÕES IN ITS TRANSLATIONS INTO ENGLISH

\begin{abstract}
The Deconstruction thinker, Jacques Derrida, dedicates part of his work to the reflection on translation. His contribution breaks with the representative translation principle especially when Derrida argues that translation constitutes the original text growth and afterlife, both of which do not happen without transforming what ought to be translated. Following this notion, we reflect on the translation of Brazilian writer Euclides da Cunha's major narrative, $O s$ sertões. For this discussion, two existent translations in English have been analyzed, the first by Samuel Putnam which dates back to 1944 and the version by Elizabeth Lowe published in 2010 .
\end{abstract}

KEYWORDS: Translation, transformation, Os sertões.

\title{
LA TRANSFORMACIÓN DE OS SERTÕES EN LAS TRADUCCIONES AL INGLÉS
}

\section{RESUMEN}

Jacques Derrida, pensador de la deconstrucción, dedica parte de su obra a la reflexión en torno a la traducción. El filósofo rompe con el ideal de traducción como representación al asumir esa actividad como maduración y supervivencia de un texto original que no suceden sin transformación de lo que se traduce. A partir de esa perspectiva, reflexionamos en torno a la traducción de la obra maestra de Euclides da Cunha, Os sertões: Campanha de Canudos. Para esta discusión, elegimos las dos traducciones al inglés, la primera, escrita en 1944, por Samuel Putnam y la más reciente, de 2010, de Elizabeth Lowe.

Palabras Clave: Traducción, transformación, Os sertões.

\section{NOTAS}

1. "At other times - the greater part of the time - his prose is not tropical, but rugged, rugged as the sertão itself; it is nervous, dramatically intense, sculptures que as the backland hills, and is characterized by a definite, brusque avoidance of lyricism and emphasis on the point of appearing overwrought and painful." 
2. "[...] a valuable contribution to the cause of cultural understanding in this hemisphere; and it is hoped that an English-language translation may serve the same end".

3. Apropriamo-nos do título Fidelidade a mais de um-merecer herdar onde a genealogia falta, que reúne considerações feitas por Jacques Derrida (2005) acerca da tradução e da sua relação estreita com a desconstrução.

4. "... how to achieve an artistic synthesis of the rich social content which his country affords him".

\section{REFERÊNCIAS}

ARROJO, Rosemary. Oficina de tradução: a teoria na prática. 4. ed. São Paulo: Ática, 1999.

BEATO, Zelina. ... no começo, a palavra. In: PIETROLUONGO, Márcia Atalia (Org.). O trabalho da tradução. Rio de Janeiro: Contra capa, 2009. p. 175-179.

BENJAMIN, Walter. A tarefa do tradutor. Tradução Susana Kampff Lages. Apêndice da tese: LAGES, Susana Kampff. Melancolia e tradução: Walter Benjamin e a tarefa do tradutor. 1996. 333 f. Tese (Doutorado em Comunicação) - Pontifícia Universidade Católica de São Paulo, São Paulo, 1996.

CATFORD, John Cunnison. Uma teoria linguística da tradução. São Paulo: Ed. Cultrix, 1980.

CUNHA, Euclides da. Rebellion in the backlands. Tradução de Samuel Putnam. Chicago: The University of Chicago Press, 1944.

Alves. 1952.

. Os sertões: Campanha de Canudos. 22. ed. Rio de Janeiro: Francisco . Backlands: the Canudos campaign. Tradução Elizabeth Lowe. Nova York: Penguin Classics, 2010.

DERRIDA, Jacques. Posições. Tradução Tomaz Tadeu da Silva. Belo Horizonte: Autêntica, 2001. 2002.

. Torres de Babel. Tradução Junia Barreto. Belo Horizonte: UFMG, . Fidelidade a mais de um: merecer herdar onde a genealogia falta. In: OTTONI, Paulo. Tradução manifesta: double bind e acontecimento. Campinas: UNICAMP, 2005. p. 165-198. 
. A verdade ofensiva ou o corpo-a-corpo das línguas. Tradução Élida Ferreira. Especiaria: cadernos de ciências humanas, v. 10, n. 17, p. 305-329, jan./jun. 2007.

GALVÃO, Walnice Nogueira. Euclidiana: ensaios sobre Euclides da Cunha. São Paulo: Companhia das Letras, 2009.

LOWE, Elizabeth. Revisiting re-translation: re-creation and historical revision. In: BERMANN, Sandra; PORTER, Catherine (Org.). A companion to translation studies. [S.I.]: Wiley-Blackwell, 2014. Disponível em: <http:// www.blackwellreference.com/public/tocnode?id=g9780470671894_chunk g978047067189431>. Acesso em: 5 set. 2015.

PUTNAM, Samuel. Brazil's greatest book: a translator's introduction. In: CUNHA, Euclides da. Rebellion in the backlands. Tradução Samuel Putnam. Chicago: The University of Chicago Press, 1944. p. iii-xviii.

SEEL, Antoine. Por trás das palavras: fluxos e ritmos em Os sertões. Tradução Jorge Coli. In: NASCIMENTO, José Leonardo do (Org.). Os sertões de Euclides da Cunha: releituras e diálogos. São Paulo: UNESP, 2002.

Submetido em 26 de outubro de 2016.

Aceito em 17 de abril de 2017.

Publicado em 30 de janeiro de 2018. 